\title{
Orthotopic heart transplant versus left ventricular assist device: A national comparison of cost and survival
}

\author{
Daniel P. Mulloy, MD, Castigliano M. Bhamidipati, DO, MSc, Matthew L. Stone, MD, \\ Gorav Ailawadi, MD, Irving L. Kron, MD, and John A. Kern, MD
}

\begin{abstract}
Objectives: Orthotopic heart transplantation is the standard of care for end-stage heart disease. Left ventricular assist device implantation offers an alternative treatment approach. Left ventricular assist device practice has changed dramatically since the 2008 Food and Drug Administration approval of the HeartMate II (Thoratec, Pleasanton, Calif), but at what societal cost? The present study examined the cost and efficacy of both treatments over time.
\end{abstract}

\begin{abstract}
Methods: All patients who underwent either orthotopic heart transplantation $(\mathrm{n}=9369)$ or placement of an implantable left ventricular assist device $(n=6414)$ from 2005 to 2009 in the Nationwide Inpatient Sample were selected. The trends in treatment use, mortality, and cost were analyzed.

Results: The incidence of orthotopic heart transplantation increased marginally within a 5-year period. In contrast, the annual left ventricular assist device implantation rates nearly tripled. In-hospital mortality from left ventricular assist device implantation decreased precipitously, from $42 \%$ to $17 \%$. In-hospital mortality for orthotopic heart transplantation remained relatively stable (range, 3.8\%-6.5\%). The mean cost per patient increased for both orthotopic heart transplantation and left ventricular assist device placement $(40 \%$ and $17 \%$, respectively). With the observed increase in both device usage and cost per patient, the cumulative Left ventricular assist device cost increased 232\% within 5 years (from $\$ 143$ million to $\$ 479$ million). By 2009, Medicare and Medicaid were the primary payers for nearly one half of all patients (orthotopic heart transplantation, $45 \%$; left ventricular assist device, $51 \%$ ).
\end{abstract}

Conclusions: Since Food and Drug Administration approval of the HeartMate II, mortality after left ventricular assist device implantation has decreased rapidly, yet has remained greater than that after orthotopic heart transplantation. The left ventricular assist device costs have continued to increase and have been significantly greater than those for orthotopic heart transplantation. Because of the evolving healthcare economics climate, with increasing emphasis on the costs and comparative effectiveness, a concerted effort at LVAD cost containment and judicious usage is essential to preserve the viability of this invaluable treatment. (J Thorac Cardiovasc Surg 2013;145:566-74)

Nearly 6 million Americans have had congestive heart failure diagnosed. ${ }^{1}$ Congestive heart failure causes more than 55,000 deaths in the United States each year, is responsible for 5\% of all medical admissions, and accounts for direct costs of more than 35 billion dollars in the United States each year. ${ }^{1,2}$ More federal funds are spent on congestive heart failure in the United States than any other diagnosis,

From the Department of Surgery, University of Virginia Health System, Charlottesville, Va.

Drs Mulloy, Bhamidipati, and Stone received support from the National Institutes of Health (grant T32: HL007849).

Disclosures: Authors have nothing to disclose with regard to commercial support.

Read at the 92nd Annual Meeting of The American Association for Thoracic Surgery, San Francisco, California, April 28-May 2, 2012.

D.P.M. and C.M.B. contributed equally to this study.

Received for publication April 30, 2012; revisions received Aug 31, 2012; accepted for publication Oct 22, 2012; available ahead of print Dec 13, 2012.

Address for reprints: John A. Kern, MD, Department of Surgery, University of Virginia Health System, 409 Lane Rd, MR4 Building, Room 3116, Charlottesville,

VA 22908 (E-mail: jak3r@ virginia.edu).

0022-5223/\$36.00

Copyright (C) 2013 by The American Association for Thoracic Surgery

http://dx.doi.org/10.1016/j.jtcvs.2012.10.034 and a disproportionate amount of these funds is spent on the treatment of advanced heart failure. ${ }^{3}$ In patients with advanced disease, the options are limited, and orthotopic heart transplantation (OHT) is widely accepted as the therapy of choice, with 1-year post-transplant survival rates of roughly $85 \%{ }^{4}$ Western societies have supported heart transplantation as an acceptable use of healthcare resources; however, the demand for this life-saving treatment far outstrips the availability of suitable donor organs. The OHT numbers in the United States have remained stable during the past decade at approximately 2000 patients treated annually, a mere fraction of the population who could benefit from this treatment. ${ }^{4}$

In 1964, the National Institutes of Health artificial heart program was created with the stated goal of putting a man-made heart into a human by the end of the decade. Despite the large investment of both public and private funds, little palpable progress was made until 2001 when the landmark Randomized Evaluation of Mechanical Assistance for the Treatment of Congestive Heart Failure (REMATCH) trial demonstrated a stark improvement in 


\section{Abbreviations and Acronyms \\ LVAD $=$ left ventricular assist device \\ OHT $=$ orthotopic heart transplantation \\ NIS $=$ Nationwide Inpatient Sample}

survival when patients with advanced heart failure underwent HeartMate XVE (Thoratec, Pleasanton, Calif) left ventricular assist device (LVAD) implantation compared with those supported with conventional medical therapy. ${ }^{5}$ In response to that trial, the Centers for Medicare and Medicaid Services authorized reimbursement for the use of Food and Drug Administration-approved LVADs as long-term destination therapy in October 2003. ${ }^{6,7}$ More recently, a second leap forward occurred with the replacement of first-generation pulsatile LVADs with newer continuousflow devices such as the HeartMate II LVAD (Thoratec), which was approved by the Food and Drug Administration for bridge-to-transplantation in April 2008 and for destination therapy in January 2010.8

Since the April 2008 approval, the HeartMate II has rapidly taken over market share as the most widely used implantable LVAD in the United States. ${ }^{10}$ Additionally, patient outcomes have rapidly improved with this newer device, with 1-year survival rates now approximately $80 \%$, a percentage almost equivalent to the reference standard of heart transplantation. ${ }^{10}$ Although it took 4 decades longer than expected, the fruits of the 1964 investment have now been realized in the form of the HeartMate II, a man-made artificial blood pump that can be successfully implanted into a human, with resulting survival rates almost equivalent to transplantation. Despite this fantastic feat of modern medicine, the cost of this achievement and feasibility of widespread use must be carefully weighed. The purpose of the present study was to examine both OHT and LVAD usage and cost patterns in the years surrounding the initial HeartMate II bridge-totransplant approval in April 2008- to shed light on current trends and possibly to help guide future use.

\section{METHODS}

\section{Data Sources}

Data were abstracted from the 2005 through 2009 Nationwide Inpatient Sample (NIS). The NIS is the largest Healthcare Cost and Utilization Project all-payer inpatient database, sponsored by the Agency for Healthcare Research and Quality. The NIS contains data from more than 8 million hospital discharges annually from 1050 hospitals located in 44 states, representing $95 \%$ of all US nonfederal hospital discharges. ${ }^{11}$ The Agency for Healthcare Research and Quality has developed appropriately scaled discharge weights to generate national estimates of hospitalizations from the NIS. ${ }^{12}$ These weights help compare hospitalization rates across years despite the varying number of states participating each year. The Healthcare Cost and Utilization Project validates the NIS for biases by comparing it with other population-based data sets. ${ }^{13}$ In the present analysis, when more than $2 \%$ of the variables for a particular record had data missing at random, we excluded the record from the computations. No imputations

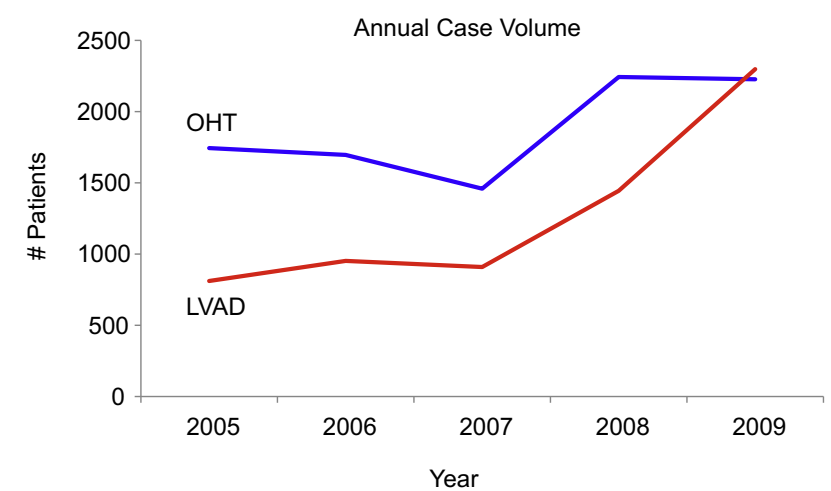

FIGURE 1. Treatment usage over time showing the number of patients undergoing either orthotopic heart transplantation $(O H T)$ or left ventricular assist device (LVAD) implantation from 2005 to 2009.

were performed, and the data sets were reviewed for any systematically missing values and accordingly excluded from evaluation. Data reporting met the NIS data use agreement as established by the Healthcare Cost and Utilization Project. The NIS databases contain de-identified administrative level data and were not considered human subjects research and, hence, were exempted from review by the University of Virginia's human investigation committee.

\section{Patient Selection}

Patients were identified based on whether they had been recipients of an OHT or an implantable LVAD. The patients were selected using the "International Statistical Classification of Diseases and Related Health Problems, 9th Revision, Clinical Modification" codes. All 15 procedure codes (PR1PR15) were queried to identify patients having undergone operative procedures using the following "International Statistical Classification of Diseases and Related Health Problems, 9th Revision, Clinical Modification" codes: OHT, 37.5 (heart replacement procedures), 37.51 (heart transplantation), 33.6 (combined heart-lung transplantation); and LVAD, 37.66 (insertion of implantable heart assist system). Only patients older than 18 years of age were selected. Those with multiple procedural codes were assigned to the groups according to the first procedure code to avoid the possibility of double counting any patient record. The records were selected only once per any given group (according to the surgical procedure) and examined with the intent to perform a comprehensive analysis of the null hypothesis. Patient risk factors were assessed using 30 different Agency for Healthcare Research and Quality comorbidities.

\section{Total Charges and Cost-to-Charge}

The total charges for each analyzed record were obtained from the Healthcare Cost and Utilization Project. Computations to calculate costs were completed by multiplying the total charges from the discharge record by the all-payer inpatient cost-to-charge ratio. These cost-to-charge ratios were calculated using annual reports by hospitals to the Centers for Medicare and Medicaid Services. The hospital-specific cost-to-charge was computed when available, and the weighted group average was used for calculations when the hospital-specific cost-to-charge was not available (approximately $11 \%$ of the time).

\section{Outcomes of Interest}

Treatment usage, in-hospital mortality, cost, and discharge disposition after OHT and LVAD were our primary outcomes of interest. Complications were identified and limited to the hospital admission-recorded "International Statistical Classification of Diseases and Related Health Problems, 9th Revision, Clinical Modification" codes. Because the NIS contains 
TABLE 1. Preoperative patient characteristics

\begin{tabular}{|c|c|c|c|c|c|c|}
\hline \multirow[b]{2}{*}{ Characteristics } & \multicolumn{2}{|c|}{2005} & \multicolumn{2}{|c|}{2006} & \multicolumn{2}{|c|}{2007} \\
\hline & OHT & LVAD & OHT & LVAD & OHT & LVAD \\
\hline Patients (n) & 1744 & 811 & 1696 & 952 & 1459 & 909 \\
\hline Age & $50.7 \pm 13.2$ & $51.6 \pm 13.8$ & $50.7 \pm 12.2$ & $53.3 \pm 12.4$ & $50.5 \pm 13.6$ & $52.9 \pm 13.6$ \\
\hline Men & 74.8 & 73.6 & 74.4 & 72.8 & 75.0 & 72.7 \\
\hline \multicolumn{7}{|l|}{ Race } \\
\hline White & 65.9 & 72.7 & 71.3 & 68.6 & 64.0 & 69.0 \\
\hline Black & 16.2 & 15.3 & 14.4 & 17.7 & 16.3 & 18.5 \\
\hline Hispanic & 8.6 & 5.1 & 6.6 & 7.5 & 12.9 & 10.7 \\
\hline Asian/Pacific Islander & 5.8 & 3.4 & 4.4 & 2.4 & 2.9 & 0.6 \\
\hline Native American & 0.4 & 1.7 & 0.8 & 0.7 & 1.6 & 0.7 \\
\hline Other & 3.2 & 1.7 & 2.6 & 3.1 & 2.4 & 0.6 \\
\hline \multicolumn{7}{|l|}{ Primary Payer } \\
\hline Medicare & 28.9 & 28.1 & 28.3 & 22.1 & 28.1 & 28.8 \\
\hline Medicaid & 11.9 & 12.5 & 13 & 11.2 & 14.9 & 14.5 \\
\hline Private insurance & 54.9 & 54.5 & 47.9 & 55 & 47.9 & 47.3 \\
\hline Other & 4.3 & 21 & 10.8 & 36.7 & 9.1 & 9.4 \\
\hline \multicolumn{7}{|l|}{ Income quartile (low to high) } \\
\hline I & 17.2 & 20.1 & 19.5 & 25.1 & 13.0 & 23.9 \\
\hline II & 23.7 & 24.3 & 27.7 & 17.4 & 21.4 & 22.0 \\
\hline III & 25.6 & 31.9 & 26.6 & 29.0 & 23.9 & 21.3 \\
\hline IV & 33.5 & 23.7 & 26.3 & 28.4 & 41.7 & 32.8 \\
\hline \multicolumn{7}{|l|}{ Comorbidities } \\
\hline HTN & 39.9 & 24.9 & 41.4 & 30 & 35 & 28.4 \\
\hline COPD & 12.7 & 14.3 & 12.3 & 9.9 & 9.0 & 14.0 \\
\hline Coagulopathy & 27.3 & 30.2 & 23.1 & 31.8 & 26.5 & 28.8 \\
\hline Depression & 10.7 & 3.7 & 9.0 & 5.3 & 5.5 & 1.1 \\
\hline Fluid and electrolyte abnormality & 36.9 & 39.0 & 38.3 & 39.6 & 40.1 & 40.2 \\
\hline Obesity & 6.1 & 5.0 & 4.8 & 5.2 & 2.6 & 3.2 \\
\hline Peripheral vascular disease & 6.1 & 4.9 & 2.4 & 2.6 & 2.1 & 3.9 \\
\hline Elective admission & 33.1 & 25.0 & 25.7 & 26.7 & 23.2 & 22.0 \\
\hline \multicolumn{7}{|l|}{ Admission source } \\
\hline Routine & 73.8 & 38.0 & 79.2 & 44.9 & 71.6 & 40.9 \\
\hline Another hospital & 14.7 & 32.9 & 13.0 & 29.7 & 16.9 & 43.5 \\
\hline ER & 9.5 & 25.4 & 7.2 & 22.9 & 11.1 & 14.4 \\
\hline Other health facility & 2.0 & 3.7 & 0.6 & 2.5 & 0.4 & 1.3 \\
\hline
\end{tabular}

Data presented as mean \pm SEM or percentages. $O H T$, Open heart transplantation; $L V A D$, left ventricular assist device; $H T N$, hypertension; $C O P D$, chronic obstructive pulmonary disease; $E R$, emergency room.

inpatient data only, complications occurring after hospital discharge could not be evaluated.

\section{Statistical Analysis}

The strength of the association between variables was examined using the appropriate hypothesis test. The significance of the differences between the unadjusted proportions for categorical variables was evaluated using the Pearson chi-square test. Differences between the mean values of unadjusted continuous variables were assessed using single-factor analysis of variance models. Unadjusted in-hospital mortality across the groups was calculated. All data were analyzed using IBM SPSS Complex Samples, version 20 (SPSS, IBM, Armonk, NY).

\section{RESULTS}

\section{Treatment Usage and Patient Characteristics}

From January 2005 to December 2009, 15,783 patients underwent either OHT or implantation of an LVAD. The trends in treatment usage have shown that OHT increased marginally during the examined period and was consistent with the widely reported $\sim 2000$ heart transplants performed annually in the United States (Figure 1). ${ }^{4}$ However, the LVAD implantation rates nearly tripled, surpassing OHT for the first time in $2009(P<.001)$. The increase in LVAD implantation rates started in 2008, the same year the Food and Drug Administration approved the continuous-flow HeartMate II LVAD. Examining the characteristics of these patients over time, several interesting observations could be made. First, both treatments were largely performed on men with an average age of about 50 years (Table 1). Most of these patients were white, but all racial groups were roughly represented in approximate proportion to their relative contributions to the US population. Across the board, black patients were slightly 
TABLE 1. Continued

\begin{tabular}{|c|c|c|c|c|c|}
\hline \multicolumn{2}{|c|}{2008} & \multicolumn{2}{|c|}{2009} & \multicolumn{2}{|c|}{ Cumulative } \\
\hline OHT & LVAD & OHT & LVAD & OHT & LVAD \\
\hline 2243 & 1444 & 2227 & 2298 & 9369 & 6414 \\
\hline $51.1 \pm 13.2$ & $55.0 \pm 13.8$ & $46.7 \pm 19.5$ & $53.4 \pm 13.8$ & $49.9 \pm 9.7$ & $53.2 \pm 9.2$ \\
\hline 74.4 & 77.9 & 77.9 & 78.0 & 75.4 & 75.9 \\
\hline 67.0 & 68.3 & 62.3 & 66.0 & 66.0 & 68.2 \\
\hline 14.1 & 15.3 & 16.7 & 20.4 & 15.5 & 17.9 \\
\hline 10.8 & 9.8 & 13.6 & 5.8 & 10.6 & 7.6 \\
\hline 6.4 & 3.5 & 4.2 & 3.2 & 4.9 & 2.8 \\
\hline 0.6 & 0.0 & 0.0 & 0.3 & 0.6 & 0.5 \\
\hline 1.1 & 3.0 & 3.2 & 4.2 & 2.5 & 2.9 \\
\hline 35.1 & 39.6 & 29.3 & 37.1 & 30.2 & 33.1 \\
\hline 14.5 & 13.3 & 15.2 & 13.5 & 14.0 & 13.1 \\
\hline 47.3 & 43.3 & 48.9 & 42.9 & 49.3 & 46.9 \\
\hline 3 & 2.7 & 6.5 & 4.6 & 6.4 & 11.7 \\
\hline 20.9 & 19.7 & 20.5 & 21.7 & 18.6 & 21.9 \\
\hline 27.7 & 28.0 & 24.4 & 27.2 & 25.2 & 24.8 \\
\hline 26.4 & 27.7 & 29.7 & 29.3 & 26.7 & 28.1 \\
\hline 25.1 & 24.6 & 25.4 & 21.9 & 29.5 & 25.2 \\
\hline 34.7 & 30.6 & 35.5 & 34.4 & 37.1 & 30.0 \\
\hline 12.1 & 13.1 & 10.2 & 14.8 & 11.3 & 13.5 \\
\hline 22.6 & 27.6 & 32.4 & 35.1 & 26.5 & 31.4 \\
\hline 11.4 & 6.5 & 8.6 & 7.4 & 9.3 & 5.5 \\
\hline 39.2 & 47.4 & 52.0 & 49.6 & 41.8 & 44.9 \\
\hline 4.2 & 5.9 & 6.5 & 10.2 & 5.0 & 6.8 \\
\hline 3.7 & 6.0 & 3.7 & 7.7 & 3.7 & 5.7 \\
\hline 20.7 & 25.6 & 24.3 & 23.5 & 25.2 & 24.4 \\
\hline 61.1 & 30.6 & 52.6 & 31.2 & 66.4 & 35.3 \\
\hline 23.3 & 47.0 & 26.0 & 52.7 & 19.5 & 44.2 \\
\hline 14.6 & 19.5 & 21.5 & 12.2 & 13.4 & 17.4 \\
\hline 1.0 & 2.9 & 0.0 & 3.7 & 0.8 & 3.0 \\
\hline
\end{tabular}

overrepresented, given that they constituted $13 \%$ of the US population as of the 2010 census (vs $16 \%$ of OHT and $18 \%$ of LVAD), and Hispanic patients were slightly underrepresented, because they constitute $16 \%$ of the US population (vs $11 \%$ of OHT and $8 \%$ of LVAD). ${ }^{14}$ All 4 income quartiles, as determined by zip code, were well represented for both LVAD and OHT, suggesting these life-saving procedures are being offered equally to eligible patients, regardless of income. As expected, patients had a variety of comorbidities, with the most common being hypertension, fluid and electrolyte abnormalities, diabetes, coagulopathy, and renal failure. Most admissions for heart transplantation were routine; however, this percentage declined over time. LVAD recipients were more likely to have been transferred from another hospital or admitted through the hospital emergency department.

\section{Mortality}

All mortality estimates examined mortality before hospital discharge only. As expected, mortality for OHT was low, ranging from $3.8 \%$ to $6.5 \%$. Mortality for LVAD implantation was high but decreased dramatically during the examined period, from $42.3 \%$ in 2005 to $17.0 \%$ in 2009 $(P<.001$; Figure 2$)$. Major improvements in the LVAD mortality rates started in 2008, the same year Food and Drug Administration approval of the HeartMate II LVAD occurred. Therefore, despite any learning curve issues that often accompany the initial use of a new device, mortality continued to decline.

\section{Cost}

All cost estimates referred to the index procedure hospitalization only and did not include the follow-up costs of 
outpatient treatment or subsequent hospitalizations. From 2005 to 2009, the unadjusted mean per-patient cost increased for both OHT and LVAD. The OHT cost increased by $40 \%$ from $\$ 120,413$ to $\$ 168,576$, and the LVAD cost increased by $17 \%$ from $\$ 177,508$ to $\$ 208,522$ (Figure 3, $A$ ). When combining the per-patient cost increases with the dramatic increase in treatment usage, the approximated nationwide annual expenditures for LVAD procedure admissions more than tripled, from $\$ 143$ million in 2005 to $\$ 479$ million in 2009 (Figure 3, B). Similarly, the approximated national OHT expenditures increased by more than $50 \%$ from $\$ 210$ million to $\$ 375$ million. When combined, the nationwide total cost of both OHT and LVAD procedure admissions was $\$ 854$ million in 2009 alone and $\$ 2.5$ billion from 2005 to 2009 . The percentage of patients receiving an OHT or LVAD who were covered by Medicare and Medicaid increased over time to roughly one half of all patients. In 2005, the approximated Medicare and Medicaid expenditures on OHT hospitalizations totaled about $\$ 85$ million. This nearly doubled, reaching roughly $\$ 167$ million in 2009. Similarly, the approximated Medicare and Medicaid expenditures on LVAD hospitalizations more than quadrupled, from $\$ 57$ million in 2005 to more than $\$ 241$ million in 2009.

\section{Disposition}

Those patients discharged alive were classified according to routine discharge to home, discharge home with home health services, discharge to a skilled nursing facility or intermediate care facility, or discharge to a rehabilitation unit or short-term hospital. The OHT survivors had routine discharge to home more frequently, and the LVAD recipients were more likely to be discharged to a skilled nursing facility or intermediate care facility or to receive home health services after discharge (Figure 4). This was perhaps not surprising, because the LVAD recipients might require increased assistance with care of the driveline exit site wound and need assistance familiarizing themselves and their families with the additional aspects of the device, including proper care of the power-based unit, control unit, batteries, and battery pack. The usage of home health services increased for both OHT and LVAD recipients throughout the study period.

\section{DISCUSSION}

The present study has shed light on evolving trends in the surgical treatment of advanced heart failure on a national level and provides reason for both great optimism and grave concern. In the 5 short years from 2005 to 2009, the LVAD implantation rates nearly tripled and in-hospital mortality decreased by more than one half. This rapid and significant decrease in procedure-related mortality on a national level is likely unprecedented and speaks to the momentous improvements being made in the field of mechanical circulatory assistance. Despite this, during the same short period, per patient, the LVAD hospitalization cost increased by $17 \%$ and the nationwide estimated LVAD hospitalization expenditures more than tripled. On the one hand, the dramatic improvement witnessed in LVAD mortality during the short study period suggests the future of LVAD therapy is bright and limitless. On the other hand, the accelerating increase in the nationwide cost of this treatment cast doubts on the future financial viability of this invaluable therapy. In presenting these data, we do not intend to argue either the former or the latter point of view. That argument rests on the question of what a life, a year, or a month is worth and was outside the scope of this project. We wish solely to point out the facts, provide information for discussion, and urge consideration of these questions as our specialty embarks on an era in which the promises of the 1964 National Institutes of Health artificial heart program are finally now a reality.

History often has a way of repeating itself, albeit with slight variations. In 1980, when considering a decision of whether Medicare would begin reimbursement for heart transplantation procedures, the Secretary of the Department of Health and Human Services, Patricia Roberts Harris, commissioned a major study to examine "all aspects of heart transplants, including the scientific, social, economic, and ethical issues, and, in particular, the impact of a possible Medicare decision to pay for heart transplants on the Medicare program, Medicare beneficiaries, and providers of health care." ${ }^{15,16}$ The Secretary further argued that Department of Health and Human Services would require future new technologies to demonstrate their beneficial "social consequences" before "financing their wide distribution." ${ }^{17}$ Fortunately, a decision was made to cover heart transplantation despite its high cost and, at the time, variable outcomes. Heart transplantation has since saved tens of thousands of lives and remains the reference standard against which all other therapies for advanced heart failure are judged. The field of mechanical circulatory assist now finds itself at a similar crossroads. Clearly, LVADs can no longer be considered merely an experimental therapy; however, their place in the larger picture of societal care of the patients with heart failure is still somewhat undefined, especially when it comes to destination therapy.

To shed insight on these considerations, multiple previous studies have addressed the issue of LVAD cost, and several have looked beyond the cost at efforts to define quality. A cost analysis of a subset of patients in the Randomized Evaluation of Mechanical Assistance for the Treatment of Congestive Heart Failure trial showed that cost of the implant-related hospitalization averaged $\$ 210,187 .{ }^{18}$ Three years later, a single-institution analysis demonstrated a reduction of $40 \%$, with implant hospitalization cost averaging $\$ 128,084$, suggesting that with experience, care could be streamlined and the cost reduced. ${ }^{6}$ A more recent study analyzed the costs of a subset of patients in the HeartMate II 


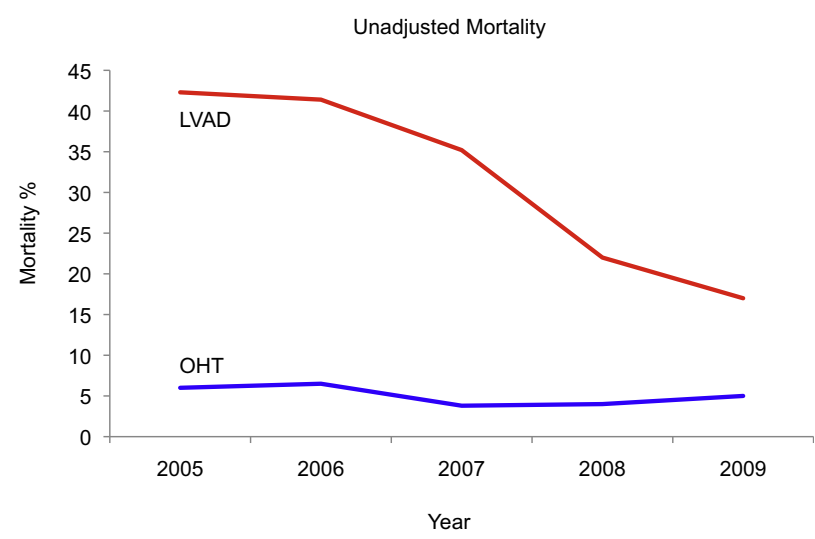

FIGURE 2. Unadjusted in-hospital mortality showing percentage of patients dying during the index hospitalization for either orthotopic heart transplantation $(O H T)$ or left ventricular assist device $(L V A D)$ implantation from 2005 to 2009 .

destination therapy trial ${ }^{19}$ and found that inflation-adjusted hospital cost averaged $\$ 193,812$, very similar to our nationwide estimates. ${ }^{20}$ In an effort to address quality, Rogers and colleagues ${ }^{21}$ recently compared the LVAD costs and outcomes with those for optimal medical management and demonstrated that although the LVAD costs were much greater for a 5 -year period ( $\$ 360,407$ vs $\$ 62,856)$, the quality-adjusted life years were also greater with LVAD (1.87 vs 0.37 ). Using these data, the incremental cost-effectiveness ratio of a continuous-flow LVAD was calculated to be $\$ 198,184$ per quality-adjusted life year. Typically, $\$ 50,000$ per qualityadjusted life year is used as the benchmark to determine adequate cost-effectiveness of a given treatment. Therefore, despite the rapid improvements being made in LVAD therapy, significant progress is still needed to meet accepted costeffectiveness benchmarks.

Although the cited studies provide useful information for a conversation on the relative merits of LVAD therapy, no previous studies have used a national database to compare LVAD cost to the standard of OHT. We believe the present study adds to the discussion by effectively providing a "bird's eye" view of the changes occurring in the surgical treatment of advanced heart failure. To determine the "social consequences" of LVAD therapy before "financing their wide distribution," this larger perspective must be captured. As healthcare distribution in the United States changes and evolves, the pressures of cost containment and comparative effectiveness will inevitably affect the availability of various treatment approaches and surgical options for patients with advanced heart failure. To remain a part of that conversation and to help influence the coming changes, our field must take a proactive approach, keeping the best interests of both our patients and our larger community in mind. With the field of mechanical circulatory assist at a crossroads, care must be taken with regard to the dissemination of this new technology. Perhaps a concerted
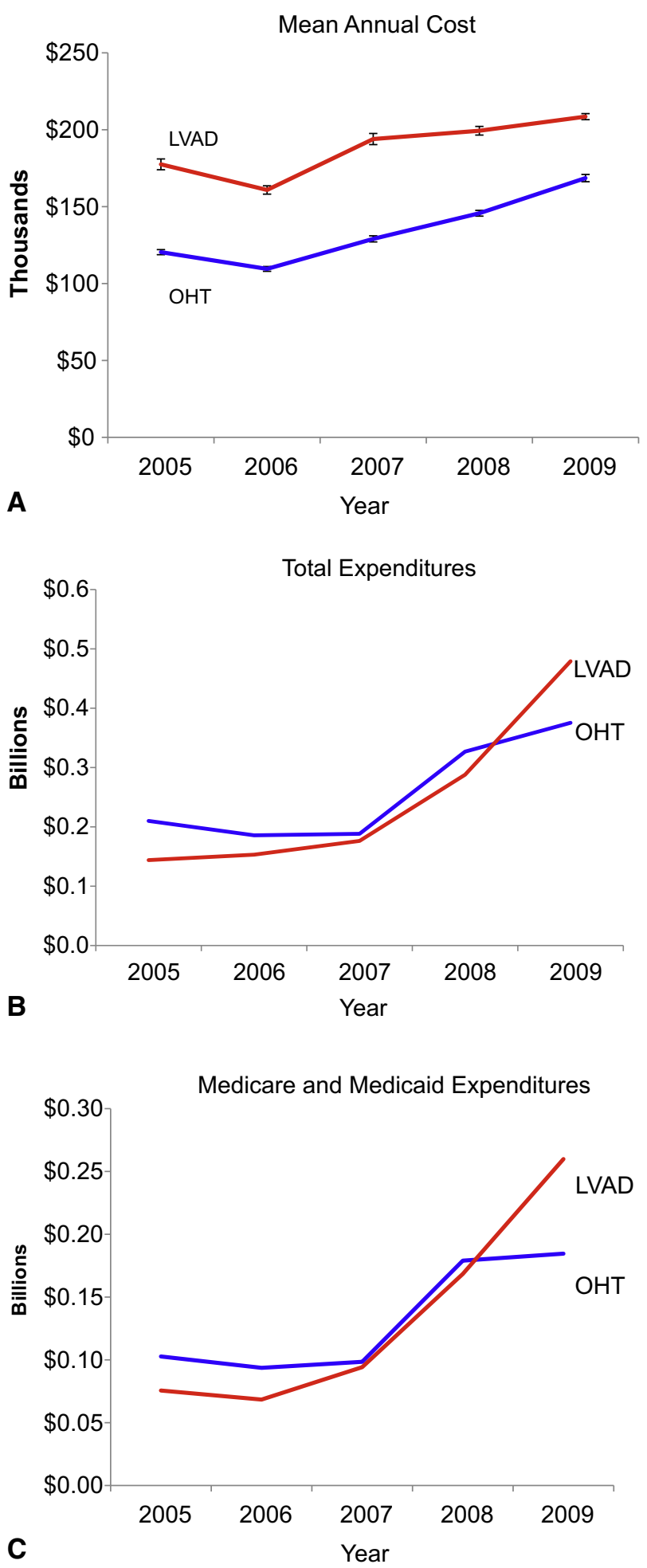

FIGURE 3. Estimated cost of index hospitalization for either orthotopic heart transplantation (OHT) or left ventricular assist device ( $L V A D)$ implantation. A, Mean per-patient cost for OHT and LVAD from 2005 to 2009, in thousands of US dollars. B, Total nationwide expenditures for OHT and LVAD index hospitalizations from 2005 to 2009, shown in billions of US dollars. C, Total Medicare and Medicaid expenditures for OHT and LVAD index hospitalizations from 2005 to 2009, shown in billions of US dollars. 

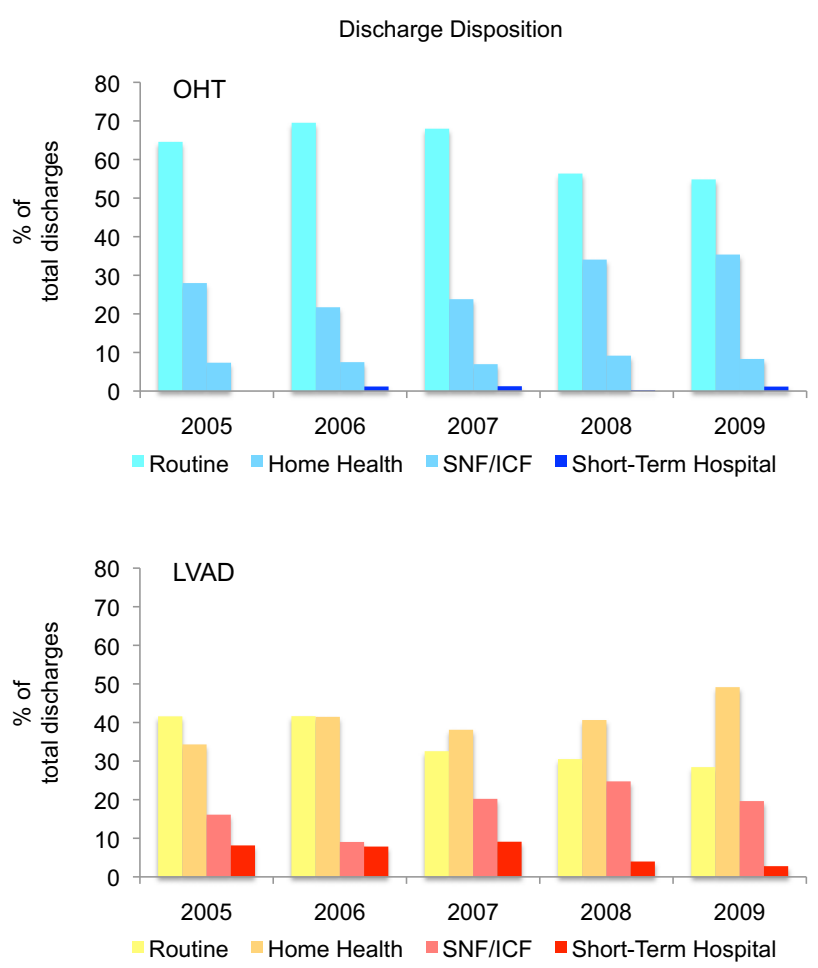

FIGURE 4. Discharge disposition of patients discharged alive after undergoing either orthotopic heart transplantation $(O H T)$ or left ventricular assist device (LVAD) implantation from 2005 to 2009. Data shown as percentages of total discharges grouped according discharge disposition: routine, home with home healthcare, skilled nursing facility or intermediate care facility $(S N F / I C F)$, and short-term hospital.

effort toward approaching established cost-effectiveness benchmarks, although improved efficiency and streamlined care, should precede the widespread use of LVAD therapy to nonheart transplant centers around the United States. Progress does not come easily in any field and especially with the future envisioned in 1964 finally now in clear view, it would be difficult to turn back. We intend to pursue the future of ventricular assist and heart transplantation but always hope to maintain a realistic awareness of the greater surroundings within which we operate.

\section{Study Limitations}

A number of potential limitations of the present study are worth noting. First, the NIS is an administrative discharge database, and patients cannot be tracked after leaving the hospital. Therefore, all cost and mortality rates reported referred to the index admission only, and we were unable to extrapolate the cost or mortality related to subsequent admissions during the same year or in succeeding years. Similarly, we could not determine which or how many LVAD recipients underwent subsequent heart transplantation. For these 2 reasons, our cost approximations have surely underestimated the true per-patient cost of these therapies. Furthermore, the NIS derives data from a $20 \%$ yearly sample of US hospitals with the sample designed to approximate the national distribution of certain hospital characteristics, including volume, academic status, location, and size. Although the NIS sampling procedure is statistically sound and has been used extensively to research national trends in healthcare delivery, elements of our presented data could reflect year-to-year sampling variations. Additionally, granularity is limited, and we could not examine individual patient characteristics. Similarly, no quality of life data were available, and we had no mechanism to compare the relative quality of life after LVAD or OHT nor could we address the quality-adjusted life years or any similar computations. Despite these potential limitations, the NIS data set allows for analysis of a large sample size with a wide geographic distribution, providing an excellent data source for examination of healthcare trends over time.

\section{CONCLUSIONS}

LVADs offer a promising alternative to OHT for those patients with advanced heart failure who are either ineligible for transplantation or for whom an acceptable donor organ is not yet available. From 2005 to 2009, the nationwide LVAD implantation rates nearly tripled, surpassing the heart transplantation rates for the first time in 2009. During the same period, mortality during the LVAD implantation hospitalization decreased from $42 \%$ to $17 \%$. Most of this growth in device usage occurred after Food and Drug Administration approval of the HeartMate II LVAD for bridge-to-transplantation in April 2008. From 2005 to 2009 , the per-patient LVAD cost increased a modest $17 \%$; however, combined with the increasing usage rates, estimated LVAD implantation expenditures increased by more than $200 \%$ to almost one half a billion dollars in 2009. In January 2010, the HeartMate II LVAD was approved for destination therapy, and newer continuous-flow devices still in development will soon follow suit. As the technology and experience progress, LVAD outcomes will continue to improve and are rapidly approaching the reference standard of heart transplantation. In the coming years, a society that has long footed the bill for heart transplantation will have to determine when, and whether, additional progress is worth the price.

\section{References}

1. Roger VL, Go AS, Lloyd-Jones DM, Benjamin EJ, Berry JD, Borden WB, et al. Heart disease and stroke statistics-2012 update: a report from the American Heart Association. Circulation. 2012;125:e2-220.

2. Heidenreich PA, Trogdon JG, Khavjou OA, Butler J, Dracup K, Ezekowitz MD, et al. Forecasting the future of cardiovascular disease in the united states: a policy statement from the American Heart Association. Circulation. 2011;123:933-44.

3. Dembitsky WP. Rematch and beyond: the cost of treating heart failure using an implantable left ventricular assist device. Semin Cardiothorac Vasc Anesth. 2006; 10:253-5. 
4. Stehlik J, Edwards LB, Kucheryavaya AY, Benden C, Christie JD, Dobbels F, et al. The registry of the International Society for Heart and Lung Transplantation: Twenty-eighth Adult Heart Transplant Report-2011. J Heart Lung Transplant. 2011;30:1078-94.

5. Rose EA, Gelijns AC, Moskowitz AJ, Heitjan DF, Stevenson LW, Dembitsky W, et al. Long-term use of a left ventricular assist device for end-stage heart failure. N Engl J Med. 2001;345:1435-43.

6. Miller LW, Nelson KE, Bostic RR, Tong K, Slaughter MS, Long JW. Hospital costs for left ventricular assist devices for destination therapy: lower costs for implantation in the post-rematch era. J Heart Lung Transplant. 2006;25:778-84.

7. Hernandez AF, Shea AM, Milano CA, Rogers JG, Hammill BG, O'Connor CM, et al. Long-term outcomes and costs of ventricular assist devices among Medicare beneficiaries. JAMA. 2008;300:2398-406.

8. Food and Drug Administration. USFaDA. Medical device approvals and clearances: Thoratec HeartMate II LVAS (p060040). Available from: http://www. fda.gov/MedicalDevices/ProductsandMedicalProcedures/DeviceApprovalsand Clearances/Recently-ApprovedDevices/ucm074231.htm. Accessed April 4, 2012.

9. Food and Drug Administration. USFaDA. Recently approved medical devices: Thoratec HeartMate II LVAS (p060040/s005). Available from: http://www.fda. gov/MedicalDevices/ProductsandMedicalProcedures/DeviceApprovalsand Clearances/Recently-ApprovedDevices/ucm201473.htm. Accessed April 4, 2012.

10. Kirklin JK, Naftel DC, Kormos RL, Stevenson LW, Pagani FD, Miller MA, et al. The fourth INTERMACS annual report: 4,000 implants and counting. J Heart Lung Transplant. 2012;31:117-26.

11. Healthcare Cost and Utilization Project. HCaUP. Overview of the nationwide inpatient sample (NIS). Available from: http://www.hcup-us.ahrq.gov/nisoverview. jsp. 2011. Accessed April 4, 2012.

12. Healthcare Cost and Utilization Project. HCaUP. Nationwide inpatient sample (NIS) database documentation. Available from: http://www.hcup-us.ahrq.gov/ db/nation/nis/nisdbdocumentation.jsp. 2011. Accessed April 2, 2012.

13. Healthcare Cost and Utilization Project. HCaUP. Healthcare cost and utilization project methods series. Available from: http://www.hcup-us.ahrq.gov/reports/ methods.jsp. 2011. Accessed April 4, 2012

14. US Census Bureau. U.S. Census Bureau 2010 USA quickfacts. Available from: http://quickfacts.census.gov/qfd/states/00000.html. 2010. Accessed April 4, 2012.

15. Knox RA. Heart transplants: to pay or not to pay. Science. 1980;209:570.

16. Newman HN. Health care Financing Administration, Medicare program: solicitation of hospitals and medical centers to participate in a study of heart transplants. Fed Reg. 1981;46:7072.

17. Evans RW. The economics of heart transplantation. Circulation. 1987;75:63-76.

18. Oz MC, Gelijns AC, Miller L, Wang C, Nickens P, Arons R, et al. Left ventricular assist devices as permanent heart failure therapy: the price of progress. Ann Surg. 2003;238:577-83, 575.

19. Slaughter MS, Rogers JG, Milano CA, Russell SD, Conte JV, Feldman D, et al. Advanced heart failure treated with continuous-flow left ventricular assist device. N Engl J Med. 2009;361:2241-51.

20. Slaughter MS, Bostic R, Tong K, Russo M, Rogers JG. Temporal changes in hospital costs for left ventricular assist device implantation. J Cardiac Surg. 2011;26:535-41.

21. Rogers JG, Bostic RR, Tong KB, Adamson R, Russo M, Slaughter MS. Cost-effectiveness analysis of continuous-flow left ventricular assist devices as destination therapy. Circ Heart Fail. 2012;5:10-6.

\section{Discussion}

Dr Ranjit John (Minneapolis, Minn). Members of the Association and guests, I appreciate the opportunity to discuss this timely, important, and well-presented report by Dr Mulloy and his colleagues. My conflict of interests include receiving grant support from Thoratec and HeartWare.

Although heart transplantation and LVADs represent therapeutic options for the same disease, namely heart failure, the applicability of both these treatments differs vastly in terms of their availability, timing, and acuity of the patients. Although studies such as these are useful and provide a good reality check on how our healthcare dollars are being spent, they sometimes ignore the fact that the LVAD groups are often a much sicker cohort of patients, who are often in need of immediate therapy.

Furthermore, I believe studies such as these do not consider the costs in terms of quality of life years, the functional improvements of LVADs, and, also, importantly, the dramatic effect that, in particular, the newer generation of LVADs have had on significantly reducing wait list mortality, now in the very low single-digit range.

Another comment includes that in the current era, the actual cost of the LVAD, I mean the pump, represents almost $50 \%$ of the overall cost, nearly $\$ 100,000$. Thus, it is possible, or perhaps feasible, that with an increased number of these devices and a more competitive environment, the costs of these devices could decrease further. I have 3 questions for you.

My first question is whether the results of your study, and you briefly mentioned it in your discussion, warrant a closer examination of the guidelines for approving centers to deliver high and expensive care such as LVADs, especially in view of a trend toward the increasing availability of LVADs as a therapeutic option?

Dr Mulloy. Regarding your question about the guidelines for LVAD availability, obviously both of these treatments are incredibly expensive, and, from our standpoint, LVADs are really not quite ready for a widespread role out in nontransplant hospitals all over the United States. Our data, and data from others, suggest that there is still some room for improvement in outcomes and, especially, in costs. We do not want to advocate, in any sense, a restriction of access but just want to ensure that this is done in a thoughtful and safe way. We do recognize that for centers to become destination therapy centers, there are a number of regulatory and quality "hoops to jump through," and I think these regulations should be embraced as a positive measure toward ensuring that the dissemination of this new technology is managed safely.

Our specialty, in general, has done a very good job of policing ourselves through the Society of Thoracic Surgeons and Interagency Registry for Mechanically Assisted Circulatory Support (INTERMACS) databases and the like. I think it is very important to continue to examine both quality and costs as LVAD therapy is expanded.

There is tremendous pressure to expand this therapy to many different centers; however, we just urge caution and focus on improving outcomes and costs before doing that on a widespread level.

Dr John. My second question relates to a study that was published last year in the Annals of Thoracic Surgery. Specifically after Food and Drug Administration approval in a study of almost 1500 HeartMate II LVADs, a significant trend was seen toward reducing mortality and improving outcomes. Do you believe we are on the right track toward improving outcomes and thereby reducing costs or could you outline points that we should be doing to further reduce costs?

Dr Mulloy. I definitely agree that as far as improving outcomes, the study you mentioned and our results both suggest that we are on that right track. We saw a decrease from $42 \%$ to $17 \%$ mortality within just a 4- or 5-year period and to see that on a national level is almost unprecedented. The outcomes are obviously rapidly improving with Food and Drug Administration approval of the HeartMate II and then with future LVADs coming down the pipeline.

However, I do not think the evidence is there to say that the costs are also improving. Theoretically, if you have a decrease in complications and have a shorter hospital stay, the cost of the procedurerelated hospitalization should definitely decrease. However, as 
patients live longer, other unforeseen costs will arise, including increased complications, such as bleeding, arrhythmias, and driveline infections. Thus, I think to say just by improving outcomes we are going to decrease costs, the evidence just is not there to say that.

Certainly, as you pointed out earlier, the cost of these devices occupy a huge portion of the total cost of this therapy. Decreasing the cost of the device would obviously help. I do not think that is going to happen without some type of external regulatory pressure. However, as devices improve, with transcutaneous batteries and elimination of the driveline and smaller devices, the potential definitely exists to decrease all those costs.

In summary, the evidence clearly shows that outcomes are improving but the costs of LVADs are not.

Dr John. My final question relates to heart transplantation. For a therapy that has not changed significantly in terms of its conduct in the past 20 years, could you speculate why the costs increased by $40 \%$ during a 4 -year period?

Dr Mulloy. That is an excellent question and thank you for pointing that out. We were surprised to see that. I do need to comment that all these costs are unadjusted costs; that is, we did not adjust for inflation, mainly because it was such a short period. Inflation from 2005 to 2009 on the national level was estimated to be about $8 \%$. Thus, we can state that $8 \%$ of that $40 \%$ might have been inflation related.

Probably more important is that a larger number of patients undergoing transplantation have pre-existing LVADs and we are probably really starting to see that in 2008 and 2009 and also going forward. I know at our institution, more than $90 \%$ of the patients currently transplanted have a pre-existing LVAD.

Although these LVAD-supported patients might be healthier on some levels, given their improved end-organ perfusion, transplantation in the setting of a LVAD definitely add some other issues. There is increased blood product use, which is extremely expensive and carries risk of additional complications. There is definitely a learning curve associated with transplantation of patients with a LVAD in place, and I think that might be where some of that cost increase occurred.

There is 1 figure that I presented in the report but did not have time for in the presentation in which we showed whether the patients were discharged routinely to home, home health, a skilled nursing facility, and so forth. During the 5 years studied, we observed an increase in both discharge with home health and discharge to skilled nursing facilities for transplant patients. Again, that trend is likely related to the additional issues associated with transplantation of patients with a pre-existing LVAD and could explain some of the observed cost increase.

Dr John. Thanks again. Excellent presentation.

Dr Matthias Loebe (Houston, Tex). Thank you very much for this very important communication. I wonder if you can comment, based on your study, on the fact that both heart transplants and LVAD implantations are covered by the same diagnosis-related group and whether it would not make more sense to separate the 2 to have a better idea of the expenses for both heart transplantations and LVAD implantations, in particular, because, today, more patients receive LVADs than heart transplants?

Dr Mulloy. I have to admit, I am a research fellow, and I am not very familiar with the diagnosis-related group or billing from the clinical standpoint. Certainly, going forward, we do need to differentiate the costs of these separate therapies and also consider the sum costs of both, which is something we were unable to do in the present study. Taking our former Vice-President as an example, obviously our estimate of $\$ 209,000$ would incredibly underestimate the total cost directed at a single patient who has received both an LVAD and a heart transplant. But, sorry, I am unable to address your specific diagnosis-related group question.

Dr Kenneth Liao (Minneapolis, Minn). My question is did you notice any difference between the INTERMACS different levels and then related with the cost? For example, INTERMACS level I would cost much more than INTERMACS level III or IV. Can you comment on that?

Dr Mulloy. That is, unfortunately, something the database prevents us from being able to study. It is definitely a limitation of a database study, in which we are relying completely on the "International Statistical Classification of Diseases and Related Health Problems, 9th Revision, Clinical Modification" codes to determine these numbers. That is a very interesting question, but it is just not something that we were able to study.

Dr Friedhelm Beyersdorf (Freiberg, Germany). I just want to make a short remark. Terminal heart failure is a huge problem, concerns the number of patients and the costs for the insurance companies to treat these patients, and these are costs go into billions per year. Of the entire sum that has to be spent for terminal heart failure treatment, less than $5 \%$ is in the direction of the surgical treatment. Thus, I just would like to encourage you to develop the surgical treatment still further. The medical treatments cost so much with rehospitalization and all the other treatments that, definitely, we can provide good service to our patients, although for the individual patients, the costs are there, and you have shown this very clearly. However, it should be seen in comparison to the overall costs.

Dr Mulloy. Thank you for making that point. We do not intend to argue that we should not push forward with LVAD or additional surgical therapy for heart failure by any means. We just want to make the point that this should be done thoughtfully, while keeping these costs in mind. We all know that the cost environment in the United States is changing, with an increased focus on comparative effectiveness, and we just want to bring these concerns to everyone's attention as something to think about as we go forward. 